\title{
Hematologic manifestations of babesiosis
}

\author{
Tamer Akel $^{1 *}$ and Neville Mobarakai ${ }^{2}$
}

\begin{abstract}
Background: Babesiosis, a zoonotic parasitic infection transmitted by the Ixodes tick, has become an emerging health problem in humans that is attracting attention worldwide. Most cases of human babesiosis are reported in the United States and Europe. The disease is caused by the protozoa of the genus Babesia, which invade human erythrocytes and lyse them causing a febrile hemolytic anemia. The infection is usually asymptomatic or self-limited in the immunocompetent host, or follows a persistent, relapsing, and/or life threatening course with multi-organ failure, mainly in the splenectomized or immunosuppressed patients. Hematologic manifestations of the disease are common. They can range from mild anemia, to severe pancytopenia, splenic rupture, disseminated intravascular coagulopathy (DIC), or even hemophagocytic lymphohistiocytosis (HLH).
\end{abstract}

Case presentation: A 70 year old immunocompetent female patient living in New York City presented with a persistent fever, night sweats, and fatigue of 5 days duration. Full evaluation showed a febrile hemolytic anemia along with neutropenia and thrombocytopenia. Blood smear revealed intraerythrocytic Babesia, which was confirmed by PCR. Bone marrow biopsy was remarkable for dyserythropoiesis, suggesting possible HLH, supported by other blood workup meeting HLH-2004 trial criteria.

Conclusion: Human babesiosis is an increasing healthcare problem in the United States that is being diagnosed more often nowadays. We presented a case of HLH triggered by Babesia microti that was treated successfully. Also, we presented the hematologic manifestations of this disease along with their pathophysiologies.

\section{Background}

Human babesiosis, an emerging zoonosis caused by the hemoparasites of the genus Babesia, the second most common blood-borne parasites of mammals after trypanosomes [2]. Infection of the human host is being diagnosed more often, probably due to increasing number of travelers, immunocompromised individuals, blood transfusions, and better diagnostic methods. The first case of human babesiosis was reported in a Yugoslavian farmer in 1956 [3]. More than 100 Babesia species infect a wide variety of domestic and wild animals, but only few infect humans [4]. The main species of Babesia that are thought to cause the majority of human babesiosis are Babesia microti, Babesia divergens and Babesia venatorum $[2,4]$.

\footnotetext{
*Correspondence: tamer.akel.88@gmail.com

${ }^{1}$ Department of Internal Medicine, Staten Island University Hospital, 475

Seaview Avenue, Staten Island, NY 10305, USA

Full list of author information is available at the end of the article
}

In the northeastern part of the US, babesiosis is usually caused by the rodent species $B$. microti, which is transmitted by the tick, Ixodes scapularis, the same tick vector responsible for the transmission of anaplasmosis and Lyme disease; and thus co-infection with Anaplasma phagocytophilum and Borrelia burgdorferi should always be considered and tested for [5]. A study of 1000 patients who are seropositive for B. burgdorferi found that $10 \%$ of them had antibodies to B. microti [6]. In Europe, human babesiosis is mainly caused by the cattle species $B$. divergens which is also transmitted by the Ixodes tick (Ixodes ricinus being the most important) [2]. The incubation period for babesiosis is somewhere between 5 and 30 days [7]. Moreover, the disease has been increasingly acquired over the past decade by blood transfusions; the incubation period in such cases has been reported to be as long as 63 days, and in one case, up to 6 months [7, 8]. The incidence of transfusion-transmitted Babesia has been reported to be about 1.1 cases per million packed 
RBCs across the United States [9]. More specifically, in endemic areas like Rhode Island, the incidence once approached 1 case per 9000 units of blood transfused [10].

The presentation of the disease is variable, ranging from subclinical, self limited asymptomatic infection to a life threatening one depending on the immune system of the host. Symptoms are usually non-specific and constitutional; initially start as fatigue, generalized weakness, and malaise, followed by abdominal pain, nausea, vomiting, photophobia, and anorexia. Hematuria and jaundice can also be observed depending on the degree of hemolysis. In a review of 139 patients hospitalized with babesiosis in New York, the most common symptoms were: fever (91\%), fatigue, malaise, and weakness (91\%), shaking chills (77\%), and diaphoresis (69\%) [11]. Physical examination is usually remarkable for fever, tachycardia or bradycardia, hepatosplenomegaly might be present, and lymphadenopathy is usually absent. The disease is more severe in splenectomized and immunosuppressed patients, and may require multiple blood transfusions or even exchange transfusion. In addition, these patients might relapse and the parasite might persist despite treatment [2].

Babesia parasites can be visualized on blood smears using the Giemsa-Wright stain. They are intraerythrocytic ring forms that resemble plasmodium, the causative agent of malaria. There are a couple of distinguishing features that can hint towards one organism over the other on light microscopy [12]. In Babesia, the parasite can form tetrads or maltese cross, although rare with $B$. microti but pathognomonic of babesiosis. In addition, Babesia does not generate hemozoin (malaria pigment) in the affected RBCs. Nevertheless, hemozoin is also not found during the early trophozoites of plasmodia. Additionally, Babesia has extracellular merozoites [12]. Furthermore, the blood smear might not show the parasites when the degree of RBCs infection is minimal i.e. $<0.01 \%$. Light microscopy has excellent sensitivity for Babesia detection, and should only be performed by an experienced microscopist, especially when thick blood smears are done, as the organisms might appear as simple chromatin dots that could be mistaken for a stain precipitate or iron inclusion bodies [13]. In the immunocompetent host, parasitemia can be hard to detect on a peripheral blood smear given that it rarely exceeds $5 \%$, in comparison to the asplenic patient where parasitemia may amount up to $85 \%[7,14]$. Other diagnostic tests can be used such as real-time quantitative PCR or conventional PCR. The detection limit of PCR is usually 50 parasites per ml, while that of light microscopy is approximately $0.001 \%$ parasitemia, which is around 5000 infected erythrocytes per $\mathrm{mL}[7,15]$. Since babesiosis typically presents with a parasitemia of $>0.1 \%$, the assay is exceedingly sensitive for the detection of most clinical specimens [1]. Antibody testing can also be used, since sero-conversion is always required for complete clearance of the parasites [16]. Nearly all infected patients will have detectable antibodies in an acute phase serum sample; this might not be the case in immunocompromised patients, however [13]. Immunofluorescence assays are used to detect titers for B. microti in specific. Titers from 1:32 to 1:160 were reported to be both diagnostic and specific, with $88-96 \%$ sensitivity, $90-100 \%$ specificity [17].

\section{Case presentation}

A 70-year-old female patient, who recently immigrated to New York City, United States of America presented to the emergency department in mid-September 2015 for episodic high grade fever associated with confusion, chills, night sweats, fatigue, nausea, headache and palpitations for 5 days. She had moved from South Korea to the United States in June 2015. Prior to presentation, she was prescribed a course of amoxicillin-clavulonic acid for three days for a possible upper respiratory tract infection. Her past medical history is remarkable only for hypertension controlled with hydrochlorothiazide. The patient denied any recent travel history, contact with pets or tick bites and stated that she lives in New York City, and occasionally visits the city's gardens next to her house. Her social history is only remarkable for smoking half a pack of cigarettes daily; she denied any alcohol or drug use. She had never been hospitalized. In the emergency department she was hypotensive, tachycardic, and febrile with a temperature of $39.3{ }^{\circ} \mathrm{C}$, a pulse of $102 \mathrm{bpm}$ and a blood pressure of $92 / 58 \mathrm{mmHg}$. She was awake, alert but not oriented. Physical examination was unremarkable except for disorientation which resolved after becoming normothermic. Her blood pressure responded to $1 \mathrm{~L}$ of normal saline.

Blood tests showed abnormal cell counts with neutropenia $\left(1.23 \times 10^{9} / \mathrm{L} ;\right.$ ANC $\left.<1.5 \times 10^{9} / \mathrm{L}\right)$, lymphopenia $\left(0.57 \times 10^{9} / \mathrm{L} ; \mathrm{ALC}<1 \times 10^{9} / \mathrm{L}\right)$, anemia (Hemoglobin of $6.8 \mathrm{~g} / \mathrm{dL} ; \mathrm{Hb}<12 \mathrm{~g} / \mathrm{dL})$, thrombocytopenia $\left(45 \times 10^{9} / \mathrm{L}\right)$, and MCV of $85 \mathrm{fL}$. Serum chemistries were all normal. Liver function tests were only remarkable for a mild elevation in total bilirubin $(1.7 \mathrm{mg} / \mathrm{dL})$ with an indirect bilirubin of $1.35 \mathrm{mg} / \mathrm{dL}$. Other blood tests showed elevated C-reactive protein $(11.6 \mathrm{mg} / \mathrm{dL}), \mathrm{LDH}$ of $476 \mathrm{IU} / \mathrm{L}$, ferritin of $1316 \mathrm{ng} / \mathrm{mL}$, reticulocyte production index of $0.7 \%$ and an undetectable haptoglobin. A blood smear was ordered on the third day of hospitalization for the evaluation of hemolysis which was only remarkable for schistocytes without any detectable parasites.

She was started on broad spectrum antibiotics for a working diagnosis of sepsis. Blood cultures were sent 
with no bacterial growth reported few days later. Imaging studies done along with a lumbar puncture were all unremarkable. Febrile hemolytic anemia was our working diagnosis with an infectious etiology being highest on our differential. Testing for HIV, EBV, CMV, Lyme disease, West Nile virus, parvovirus B19, Anaplasma phagocytophilum and Babesia microti were all sent out, but took at least four days to get reported. Meanwhile, an immunological workup done was also unremarkable. Direct coombs test was negative.

She was actively hemolyzing with persistently daily high grade fevers despite antibiotics. The patient was given steroids for possible coombs negative autoimmune hemolysis without any response. During her 10 day hospital stay she required multiple RBCs' transfusions to keep the hemoglobin above $7 \mathrm{mg} / \mathrm{dL}$. Bone marrow biopsy was performed on the fourth day of hospitalization which showed dyserythropoeisis. She continued to be pancytopenic; repeat blood smear on the seventh day showed intraerythrocytic Babesia in $4 \%$ of the RBCs. Infectious serology testing on blood using IFA sent initially was remarkable for positive IgM antibodies against $B$. microti with a titer of 1:256 along with a positive realtime PCR for the $18 \mathrm{~S}$ rRNA gene [1]. Atovaquone $750 \mathrm{mg}$ every $12 \mathrm{~h}$ orally and Clindamycin $600 \mathrm{mg}$ every $8 \mathrm{~h}$ were started and the patient responded well. After 10 days of hospitalization, the patient was discharged, and followed up with an outside physician who reported that she was doing well. Repeated CBC showed resolution of the hemolytic anemia. A follow up peripheral blood smear was clear of hemoparasites.

\section{Discussion}

Human babesiosis is increasingly seen more often among the immunocompetent host, especially in the aging population. Age related decline in cellular immunity might help explain the severity of babesiosis in patients older than 50 years of age [4]. This can be reflected by a mouse model which showed age-associated loss of immunity against $B$. microti [18]. The patient we presented was an elderly woman without any other known risk factors. However, she followed a moderate-to-severe course of the disease and became transfusion-dependant on a daily basis for one week.

Clinical manifestations of severe babesiosis can have multiple complications; these include acute respiratory failure, non-cardiogenic edema, congestive heart failure, renal failure, DIC, splenic infarction or even HLH. Complications can occur early or late in the course of the disease. One review of 34 cases of babesiosis who were hospitalized in Long Island confirmed that acute respiratory failure is the most common complication (happened in 7 out of 34 cases), followed by DIC (happened in 6 out of 34 cases) [19].
An extremely rare, yet can be a fatal complication of babesiosis is HLH. HLH is likely an under-diagnosed disease that can result in multi-organ failure and death [20]. It is a condition characterized by excessive inflammation, hypercytokinemia, abnormal immune activation and tissue destruction. This results from a lack of normal downregulation of activated macrophages and lymphocytes [21]. The dysregulation is due to the inability of natural killer cells and cytotoxic lymphocytes to eliminate the activated macrophages. This dysregulation along with the excessive secretion of cytokines cause tissue damage. HLH is classified into a primary form and a secondary form. The primary form typically manifests in young adults with genetic abnormalities of the cytotoxic function of natural killer cells and $\mathrm{T}$ cells. The secondary form of the disease occurs in older people who usually have an underlying condition, such as infection, malignancy or an autoimmune disorder without any identifiable genetic defect. Infectious diseases associated with HLH include epstein-barr virus, cytomegalovirus, human herpes virus-8, herpes simplex virus, varicella-zoster virus, $\mathrm{H} 1 \mathrm{~N} 1$ influenza virus, measles virus, parechovirus, parvovirus, and HIV. Leishmaniasis has also been reported to precipitate $\mathrm{HLH}$, although more reported in the pediatric population.

The diagnostic criteria have been derived from the HLH-2004 trial [22]. Five out of the 8 criteria listed in Table 1 need to be met to diagnose HLH [22, 23].

It should also be noted that these diagnostic criteria were used in clinical trials, and thus may not identify every single case of HLH. In the literature, there are only 4 cases reported since 1986 with HLH secondary to babesiosis. The first reported case was in a patient with cryptosporidium infection [25]. The second case was

\section{Table 1 Diagnostic criteria for HLH used in the HLH-2004 trial}

Five of the eight criteria listed below should be fulfilled

Fever $\geq 38.5^{\circ} \mathrm{C}$

Splenomegaly

Cytopenias (affecting at least 2 of 3 lineages in the peripheral blood)

Hemoglobin $<9 \mathrm{~g} / \mathrm{dL}$ (in infants $<4$ weeks: hemoglobin $<10 \mathrm{~g} / \mathrm{dL}$ )

Platelets $<100 \times 10^{3} / \mathrm{mL}$

Neutrophils $<1 \times 10^{3} / \mathrm{mL}$

Hypertriglyceridemia (fasting, $>265 \mathrm{mg} / \mathrm{dL}$ ) and/or hypofibrinogenemia $(<150 \mathrm{mg} / \mathrm{dL})$

Hemophagocytosis in bone marrow, spleen, lymph nodes, or liver ${ }^{a}$ Ferritin $>500 \mathrm{ng} / \mathrm{mL}$

Elevated SCD25 (a-chain of sIL-2 receptor)

Low or absent NK-cell activity

a Findings in up to two-thirds of initial bone marrow aspirates may be nondiagnostic; an additional bone marrow finding includes dyserythropoiesis, which has been observed in the absence of hemophagocytic histiocytes [24] 
in an asplenic renal transplant patient on immunosuppressive therapy [26, 27]. Another case report suggested a possible HLH in a man with amyopathic dermatomyositis and ILD who is on rituximab therapy [28]. The last case report was a possible HLH in an immunocompetent patient who presented with severe pancytopenia and hemophagocytosis on bone marrow biopsy [29]. In our case, the patient had pancytopenia, fever, dyserythropoiesis, hypofibrinogenemia, and a high ferritin level meeting the criteria defined by HLH-2004 trial. Hence, we hypothesize that he had HLH triggered by Babesia. When HLH is triggered by acute infection, and the patient is stable, the appropriate therapy is removal of the stimulus that is activating the immune system. This strategy may allow patients to avoid HLH specific therapy which is potentially toxic and should be reserved for patients who are severely ill. However, in our case, we highlight the role of prednisone given initially, as it is difficult to conclude whether it had a role on the disease itself. Corticosteroids are part of the initial therapy for $\mathrm{HLH}$, since it has a role in controlling the over-activation of the immune system. Conversely, since the precipitating etiology in our case was infectious, it is difficult to tell whether steroids had a role in exacerbating the disease, or whether it was beneficial in preventing progression to severe HLH. In Table 2, we compare our case to other reported cases of babesiosis in the literature using the HLH criteria.

Hematologic manifestations of Babesia are common in the human host. Thrombocytopenia is one of its major features. It is usually caused by hypersplenism which results in increased platelet sequestration and destruction by splenic macrophages [30]. In severe babesiosis, thrombocytopenia could be secondary to DIC. Immune mediated destruction of platelets has also been reported along with autoimmune hemolytic anemia [31]. Shatzel et al. reported two cases of Evans syndrome, the first one had a history of Hodgkin's lymphoma in remission, along with a history of autoimmune hemolytic anemia 12 years prior to presentation which was treated with splenectomy; he presented again with severe AIHA and thrombocytopenia, but this time after getting infected with Babesia [31]. The second patient had a history of Evans Syndrome treated with splenectomy, but relapsed three weeks post-splenectomy after a babesial infection [31]. Many other case reports described AIHA in patients with babesiosis; this leads us to conclude that there might be an element of immune deregulation precipitated by Babesia [19, 31-34].

Anemia (defined her as hemoglobin $\leq 10 \mathrm{~g} / \mathrm{dL}$ ) is another well documented hematologic abnormality in babesiosis. Its presence is associated with further complications [19]. Anemia happens after the egress of the parasite from RBCs causing lysis. Hemolysis alone does not really explain the severity of the anemia, since it is more pronounced than the level of parasitemia usually. Otsuka et al. found that cultures of parasitized RBCs of dogs with Babesia gibsoni had a significantly higher production of superoxide, which indicates that lipid peroxidation was greater in the infected cells and thus clarifying the role of oxidative damage in host erythrocytes; this could also be the case in human RBCs [35, 36]. There could also be an element of autoimmune hemolysis triggered by Babesia as described previously.

Table 2 Reported cases of HLH and babesiosis (Babesia microti) with our case

\begin{tabular}{|c|c|c|c|c|c|}
\hline Author, year (Ref.) & Auerbach et al. [25] & $\begin{array}{l}\text { Gupta et al. [27] Slovut } \\
\text { et al. [26] }\end{array}$ & Poisnel et al. [29] & Mecchella et al. [28] & Our case \\
\hline Underlying disease & Cryptosporidium & Renal transplant & None & $\begin{array}{l}\text { Amyopathic DM and } \\
\text { ILD }\end{array}$ & None \\
\hline Medication & None & Prednisone, azathioprine & None & $\begin{array}{l}\text { Rituximab/MMF/pred- } \\
\text { nisone }\end{array}$ & Prednisone \\
\hline Parasitemia \% & 7 & 13 & 3 & $<1$ & 4 \\
\hline $\begin{array}{l}\text { Cytopenia (as per HLH- } \\
\text { 2004) }\end{array}$ & No & Yes & Yes & Yes & Yes \\
\hline Ferritin, ng/mL & Not reported & Not reported & 5953 & 1665 & 1316 \\
\hline Fibrinogen, mg/dL & Not reported & Not reported & Not reported & Not reported & 98 \\
\hline Bone marrow biopsy & $\begin{array}{l}\text { Hemophagocytic his- } \\
\text { tiocytes }\end{array}$ & $\begin{array}{l}\text { Hemophagocytic } \\
\text { histiocytes }\end{array}$ & $\begin{array}{l}\text { Hemophagocytic } \\
\text { histiocytes }\end{array}$ & Not done & Dyserythropoiesis \\
\hline $\mathrm{LDH}$, units/L & 485 & 3510 & 620 & 586 & 476 \\
\hline Haptoglobin mg/dL & Not reported & $<3$ & Undetectable & $<10$ & $<3$ \\
\hline Splenomegaly & Yes & Asplenic & & Not reported & No \\
\hline Fever & Yes & Yes & Yes, value not reported & Yes, but low grade & Yes \\
\hline Coombs test & Not reported & Positive & Not reported & Negative & Negative \\
\hline
\end{tabular}


In addition, the reticulocyte count is usually high to compensate for hemolysis, however, it can also be low as in our patient suggesting a bone marrow complication like HLH. If the patient has severe anemia, partial or complete red cell exchange transfusion is recommended as per the guidelines of the IDSA in the context of high levels of parasitemia $(\geq 10 \%)$; or if the patient has any signs of end organ damage [13].

White blood cell involvement can also happen. Lymphopenia is a common finding among patients with babesiosis, one report described 17 patients with documented babesiosis; among them 13 where identified as lymphopenic [37]. Neutropenia on the other hand is not listed as a common hematologic finding associated with babesiosis [4]. On this contrary some clinicians may view neutropenia as inconsistent with babesiosis leading them to search for another cause [38]. One report assessed the frequency of neutropenia among 51 adult patients who were diagnosed with babesiosis between 2010 and 2013, 18 of them had neutropenia defined as an absolute neutrophil count $\leq 1800$ neutrophils/ $\mu \mathrm{L}$ [38]. Mechanisms of WBCs involvement is yet to be clarified whether it's a result of direct damage to the hematopoietic precursor cells, increased neutrophil adherence, splenic sequestration or a combination of all. In fact a high WBC count i.e. more than $5 \times 10^{9} / \mathrm{L}$ is a strong predictor of severe babesiosis [11].

The spleen is a vital organ in clearing erythrocytes infected with Babesia, and its absence is a major risk factor for severe infection. The role of the spleen can be illustrated by the mechanism of sequestration, since the parasitized erythrocytes lack the deformability needed to transit the splenic sinusoids and are therefore sequestered within the spleen by resident macrophages [39]. Complications involving this organ can happen, more specifically splenic infarction or rupture. In reviewing the literature we found 11 cases with this complication. Table 3 summarizes these cases.
Accordingly, we conclude that babesiosis can cause splenic rupture, just like malaria which is a well documented cause of this pathology. Mechanisms for malarial splenic rupture may also apply to babesiosis. During infection, pro-inflammatory cytokines are released, specifically TNF, IL-1, IL-6 and IFN-g leading to increased expression of adhesion molecules on the surface of the vascular endothelium. This in turn results in cytoadherence of the infected erythrocytes to the vascular endothelium causing erythrocyte sequestration and obstruction of the vascular flow [48]. In addition, hyperplasia of the reticuloendothelial system may lead to sub-capsular hemorrhage, and eventual splenic capsule breakdown with rupture into the peritoneoum [46]. Conversely, one report examined tissue sections from a splenectomized patient who died from multi-organ failure resulting from severe babesiosis. None of the parasitized erythrocytes examined were close enough to the vascular walls to suggest any degree of sequesteration [49]. Animal models confirmed sequestration of infected erythrocytes (with $B$. gibsoni and Babesia WA-1) over the capillary endothelial cells $[50,51]$. This has to be clarified by more histological sections in the human host. It is reasonable to conclude from published cases of splenic rupture that this is a complication of the immunocompetent individual. Since all cases had some degree of splenomegaly, it is possible to hypothesize that the development of subclinical splenomegaly due to splenic erythrophagocytosis may render the spleen more susceptible to spontaneous rupture with minor trauma $[39,42]$.

\section{Conclusion}

The incidence of human babesiosis is increasing in the United States, mainly in endemic regions like the Northeastern part. The present case illustrates the importance of considering blood-borne infections in patients presenting with febrile hemolytic anemia. We conclude that human babesiosis is a well documented cause of

Table 3 Reported cases of splenic rupture due to babesiosis

\begin{tabular}{|c|c|c|c|}
\hline Author, year (Ref.) & Splenomegaly & Immunity status & Urgent splenectomy \\
\hline Siderits et al. [39] & Had splenomegaly & Immunocompetent & Yes \\
\hline Florescu et al. [40] & 2 cases both had splenomegaly & 2 cases both are immunocompetent & No \\
\hline Kuwayama and Briones [41] & Subclinical splenomegaly & Immunocompetent & Yes \\
\hline Froberg et al. [42] & Had splenomegaly & Immunocompetent & Yes \\
\hline Reis et al. [43] & Not reported & Immunocompetent & Treated by splenic artery embolization \\
\hline El Khoury et al. [44] & 2 cases both had splenomegaly & 2 cases both are immunocompetent & No \\
\hline Tobler Jr. et al. [45] & Had splenomegaly & Immunocompetent & No \\
\hline Seible et al. [46] & Not reported & Immunocompetent & No \\
\hline Farber et al. [47] & Subclinical splenomegaly & Immunocompetent & Yes \\
\hline
\end{tabular}


pancytopenia, hemolysis, splenic rupture and should be considered as a potentially treatable cause of $\mathrm{HLH}$.

\begin{abstract}
Abbreviations
AlHA: autoimmune hemolytic anemia; ALC: absolute lymphocyte count; ANC: absolute neutrophile count; CBC: complete blood count; CMV: cytomegalovirus; DIC: disseminated intravascular coagulopathy; EBV: epstein barr virus; $\mathrm{Hb}$ : hemoglobin; HIV: human immunodefieicny virus; HLH: hemophagocytic Iymphohistiocytosis; IDSA: Infectious Diseases Society of America; IFA: immunofluorescence assay; IL: interleukin; ILD: interstitial lung disease; LDH: lactate dehydrogenase; MCV: mean corpuscular volume; NK: natural Killer; PCR: polymerase chain reaction; RBC: red blood cells; WBC: white blood cells.
\end{abstract}

\section{Author details}

1 Department of Internal Medicine, Staten Island University Hospital, 475 Seaview Avenue, Staten Island, NY 10305, USA. ${ }^{2}$ Department of Infectious Diseases, Staten Island University Hospital, 475 Seaview Avenue, Staten Island, NY 10305, USA.

\section{Acknowledgements}

The authors gratefully acknowledge Mrs. Katrina Tohme for her technical and linguistic support.

\section{Competing interests}

The authors declare that they have no competing interests.

Received: 31 August 2016 Accepted: 3 January 2017

Published online: 15 February 2017

\section{References}

1. Teal AE, Habura A, Ennis J, Keithly JS, Madison-Antenucci S. A new realtime PCR assay for improved detection of the parasite Babesia microti. J Clin Microbiol. 2012;50(3):903-8.

2. Hildebrandt A, Gray JS, Hunfeld KP. Human babesiosis in Europe: what clinicians need to know. Infection. 2013;41(6):1057-72.

3. Skrabalo Z, Deanovic Z. Piroplasmosis in man; report of a case. Doc Med Geogr Trop. 1957;9(1):11-6.

4. Vannier E, Krause PJ. Human babesiosis. N Engl J Med. 2012;366(25):2397-407.

5. Weiss LM. Babesiosis in humans: a treatment review. Expert Opin Pharmacother. 2002;3(8):1109-15.

6. Krause PJ, Telford SR, Spielman A, Sikand V, Ryan R, Christianson D, Burke G, Brassard P, Pollack R, Peck J, Persing DH. Concurrent Lyme disease and babesiosis. Evidence for increased severity and duration of illness. JAMA. 1996:275(21):1657-60

7. Rozej-Bielicka W, Stypulkowska-Misiurewicz H, Golab E. Human babesiosis. Przegl Epidemiol. 2015;69(3):489-94.

8. Herwaldt BL, Linden JV, Bosserman E, Young C, Olkowska D, Wilson M. Transfusion-associated babesiosis in the United States: a description of cases. Ann Intern Med. 2011;155(8):509-19.

9. Tonnetti L, Eder AF, Dy B, Kennedy J, Pisciotto P, Benjamin RJ, Leiby DA. Transfusion complicationS: transfusion-transmitted Babesia microti identified through hemovigilance. Transfusion. 2009;49(12):2557-63.

10. Asad S, Mermel L, Sweeney J. Transfusion transmitted babesiosis in Rhode Island, Transfusion. Oxford: Blackwell Publishing; 2008. p. 32A-3A.

11. White DJ, Talarico J, Chang HG, Birkhead GS, Heimberger T, Morse DL. Human babesiosis in New York State: review of 139 hospitalized cases and analysis of prognostic factors. Arch Intern Med. 1998;158(19):2149-54

12. Bonoan JT, Johnson DH, Cunha BA. Life-threatening babesiosis in an asplenic patient treated with exchange transfusion, azithromycin, and atovaquone. Heart Lung. 1998;27(6):424-8.

13. Wormser GP, Dattwyler RJ, Shapiro ED, Halperin JJ, Steere AC, Klempner MS, Krause PJ, Bakken JS, Strle F, Stanek G, Bockenstedt L, Fish D, Dumler JS, Nadelman RB. The clinical assessment, treatment, and prevention of lyme disease, human granulocytic anaplasmosis, and babesiosis: clinical practice guidelines by the Infectious Diseases Society of America. Clin Infect Dis. 2006;43(9):1089-134

14. Martinot M, Zadeh MM, Hansmann Y, Grawey I, Christmann D, Aguillon S, Jouglin M, Chauvin A, De Briel D. Babesiosis in immunocompetent patients, Europe. Emerg Infect Dis. 2011;17(1):114-6.

15. Beugnet F, Moreau Y. Babesiosis. Rev Sci Tech. 2015;34(2):627-39.

16. Ruebush TK, Chisholm ES, Sulzer AJ, Healy GR. Development and persistence of antibody in persons infected with Babesia microti. Am J Trop Med Hyg. 1981;30(1):291-2.

17. Krause PJ, Telford SR, Ryan R, Conrad PA, Wilson M, Thomford JW, Spielman A. Diagnosis of babesiosis: evaluation of a serologic test for the detection of Babesia microti antibody. J Infect Dis. 1994;169(4):923-6.

18. Vannier E, Borggraefe I, Telford SR, Menon S, Brauns T, Spielman A, Gelfand $\mathrm{JA}$, Wortis $\mathrm{HH}$. Age-associated decline in resistance to Babesia microti is genetically determined. J Infect Dis. 2004;189(9):1721-8.

19. Hatcher JC, Greenberg PD, Antique J, Jimenez-Lucho VE. Severe babesiosis in Long Island: review of 34 cases and their complications. Clin Infect Dis. 2001;32(8):1117-25.

20. Rosado FG, Kim AS. Hemophagocytic lymphohistiocytosis: an update on diagnosis and pathogenesis. Am J Clin Pathol. 2013;139(6):713-27.

21. Filipovich A, McClain K, Grom A. Histiocytic disorders: recent insights into pathophysiology and practical guidelines. Biol Blood Marrow Transplant. 2010;16(1 Suppl):S82-9.

22. Henter II, Horne A, Arico M, Egeler RM, Filipovich AH, Imashuku S, Ladisch S, McClain K, Webb D, Winiarski J, Janka G. HLH-2004: diagnostic and therapeutic guidelines for hemophagocytic lymphohistiocytosis. Pediatr Blood Cancer. 2007:48(2):124-31.

23. Jordan MB, Allen CE, Weitzman S, Filipovich AH, McClain KL. How I treat hemophagocytic lymphohistiocytosis. In: Blood, vol 118. Washington, DC; 2011. p 4041-52.

24. Schwartz RA, Coppes M. Lymphohistiocytosis (Hemophagocytic Lymphohistiocytosis). 2011.

25. Auerbach M, Haubenstock A, Soloman G. Systemic babesiosis. Another cause of the hemophagocytic syndrome. Am J Med. 1986;80(2):301-3.

26. Slovut DP, Benedetti E, Matas AJ. Babesiosis and hemophagocytic syndrome in an asplenic renal transplant recipient. Transplantation. 1996:62(4):537-9.

27. Gupta P, Hurley RW, Helseth PH, Goodman JL, Hammerschmidt DE. Pancytopenia due to hemophagocytic syndrome as the presenting manifestation of babesiosis. Am J Hematol. 1995;50(1):60-2.

28. Mecchella JN, Rigby WF, Zbehlik AJ. Pancytopenia and cough in a man with amyopathic dermatomyositis. Arthritis Care Res (Hoboken). 2014;66(10):1587-90.

29. Poisnel E, Ebbo M, Berda-Haddad Y, Faucher B, Bernit E, Carcy B, Piarroux R, Harle JR, Schleinitz N. Babesia microti: an unusual travel-related disease. BMC Infect Dis. 2013;13:99.

30. Pantanowitz L. Mechanisms of thrombocytopenia in tick-borne diseases. Internet J Infect Dis. 2003:2(2)

31. Shatzel JJ, Donohoe K, Chu NQ, Garratty G, Mody K, Bengtson EM, Dunbar NM. Profound autoimmune hemolysis and Evans syndrome in two asplenic patients with babesiosis. Transfusion. 2015;55(3):661-5.

32. Evenson DA, Perry E, Kloster B, Hurley R, Stroncek DF. Therapeutic apheresis for babesiosis. J Clin Apher. 1998;13(1):32-6.

33. Wolf CF, Resnick G, Marsh WL, Benach J, Habicht G. Autoimmunity to red blood cells in babesiosis. Transfusion. 1982;22(6):538-9.

34. Herman JH, Ayache S, Olkowska D. Autoimmunity in transfusion babesiosis: a spectrum of clinical presentations. J Clin Apher. 2010;25(6):358-61.

35. Otsuka Y, Yamasaki M, Yamato $O$, Maede $Y$. Increased generation of superoxide in erythrocytes infected with Babesia gibsoni. J Vet Med Sci. 2001;63(10):1077-81.

36. Otsuka Y, Yamasaki M, Yamato O, Maede Y. The effect of macrophages on the erythrocyte oxidative damage and the pathogenesis of anemia in Babesia gibsoni-infected dogs with low parasitemia. JVet Med Sci. 2002;64(3):221-6.

37. Kim N, Rosenbaum GS, Cunha BA. Relative bradycardia and lymphopenia in patients with babesiosis. Clin Infect Dis. 1998;26(5):1218-9.

38. Wormser GP, Villafuerte P, Nolan SM, Wang G, Lerner RG, Saetre KL, Maria $\mathrm{MH}$, Branda JA. Neutropenia in congenital and adult Babesiosis. Am J Clin Pathol. 2015;144(1):94-6.

39. Siderits R, Mikhail N, Ricart C, Abello-Poblete MV, Wilcox C, Godyn JJ. Babesiosis, Significance of spleen function illustrated by postsplenectomy course in 3 cases. Infect Dis Clin Pract. 2008;16(3):182-6. 
40. Florescu D, Sordillo PP, Glyptis A, Zlatanic E, Smith B, Polsky B, Sordillo E. Splenic infarction in human babesiosis: two cases and discussion. Clin Infect Dis. 2008;46(1):e8-11.

41. Kuwayama DP, Briones RJ. Spontaneous splenic rupture caused by Babesia microti infection. Clin Infect Dis. 2008:46(9):e92-5.

42. Froberg MK, Dannen D, Bernier N, Shieh WJ, Guarner J, Zaki S. Case report: spontaneous splenic rupture during acute parasitemia of Babesia microti. Ann Clin Lab Sci. 2008;38(4):390-2.

43. Reis SP, Maddineni S, Rozenblit G, Allen D. Spontaneous splenic rupture secondary to Babesia microti infection: treatment with splenic artery embolization. In J Vasc Interv Radiol, United States. 2011:22:732-4.

44. El Khoury MY, Gandhi R, Dandache P, Lombardo G, Wormser GP. Nonsurgical management of spontaneous splenic rupture due to Babesia microti infection. Ticks Tick Borne Dis. 2011;2(4):235-8.

45. Tobler WD Jr, Cotton D, Lepore T, Agarwal S, Mahoney EJ. Case Report: successful non-operative management of spontaneous splenic rupture in a patient with babesiosis. World J Emerg Surg. 2011;6:4.

46. Seible DM, Khatana SA, Solomon MP, Parr JB. Hoof beats may mean zebras: atraumatic splenic rupture. Am J Med. 2013;126(9):778-80.
47. Farber FR, Muehlenbachs A, Robey TE. Atraumatic splenic rupture from Babesia: a disease of the otherwise healthy patient. Ticks Tick Borne Dis. 2015;6(5):649-52

48. Krause PJ, Daily J, Telford SR, Vannier E, Lantos P, Spielman A. Shared features in the pathobiology of babesiosis and malaria. Trends Parasitol. 2007;23(12):605-10.

49. Clark IA, Budd AC, Hsue G, Haymore BR, Joyce AJ, Thorner R, Krause PJ. Absence of erythrocyte sequestration in a case of babesiosis in a splenectomized human patient. Malar J. 2006;5:69.

50. O'Connor RM, Long JA, Allred DR. Cytoadherence of Babesia bovisinfected erythrocytes to bovine brain capillary endothelial cells provides an in vitro model for sequestration. Infect Immun. 1999;67(8):3921-8.

51. Dao AH, Eberhard ML. Pathology of acute fatal babesiosis in hamsters experimentally infected with the WA-1 strain of Babesia. Lab Invest. 1996;74(5):853-9.

\section{Submit your next manuscript to BioMed Central and we will help you at every step:}

- We accept pre-submission inquiries

- Our selector tool helps you to find the most relevant journal

- We provide round the clock customer support

- Convenient online submission

- Thorough peer review

- Inclusion in PubMed and all major indexing services

- Maximum visibility for your research

Submit your manuscript at www.biomedcentral com/submit 